\title{
Myosin Heavy Chain Expression and Oxidative Modifications in Diabetic Rat Hearts
}

\author{
Mai Kuratani ${ }^{1}$, Keita Kanzaki ${ }^{2}$, Noriyuki Yanaka ${ }^{3}$, Satoshi Matsunaga ${ }^{4}$, Masanobu Wada ${ }^{1}$ \\ ${ }^{1}$ Graduate School of Integrated Arts and Sciences, Hiroshima University, Hiroshima, Japan \\ ${ }^{2}$ Faculty of Food Culture, Kurashiki-Sakuyo University, Okayama, Japan \\ ${ }^{3}$ Graduate School of Biosphere Science, Hiroshima University, Hiroshima, Japan \\ ${ }^{4}$ Faculty of Education and Culture, Miyazaki University, Miyazaki, Japan \\ Email: wada@hiroshima-u.ac.jp
}

Received August 27, 2012; revised September 29, 2012; accepted October 11, 2012

\begin{abstract}
In this study, we tested the hypotheses that 1) diabetes-induced disturbances in cardiac my-ATPase activity would be attributed to not only myosin heavy chain (MHC) isoform transitions, but also reduced amounts in MHC protein; and 2) if diabetes results in declines in the MHC protein content, this change would relate to oxidative damage to MHC. Diabetes was induced by a single intraperitoneal injection of streptozotocin. After 6 weeks of injection, the left ventricles were excised for mechanical and biochemical analyses. Peak twitch tension and the rate of force development in papillary muscles were decreased by $23.4 \%$ and $34.1 \%$, respectively. A $33.5 \%$ reduction in myofibrillar ATPase activity occurred in conjunction with a $9.5 \%$ decrease in MHC protein as well as MHC isoform transitions towards a slower phenotype. The decreased MHC content was not accompanied by elevations in carbonyl groups present in MHC. Whole muscle analyses indicated that the contents of malondialdehyde and reduced glutathione were elevated. These results suggest that decreases in the MHC content may be associated, at least in part, with a diabetes-related inactivation of cardiac my-ATPase and may not be due to accumulation of oxidative damage to protein.
\end{abstract}

Keywords: Myofibrillar ATPase; Reactive Oxygen Species; Protein Degradation; Isomyosin

\section{Introduction}

The prevalence of diabetes mellitus is growing rapidly from 170 million in 2000 to an estimated 366 million in 2030 [1]. Patients with diabetes are at increased risk for cardiovascular diseases. Diabetes mellitus can induce abnormalities in ventricular muscle independent of changes in blood pressure and coronary artery disease, a condition called "diabetic cardiomyopathy". Prominent defects of diabetic cardiomyopathy include slowing of contraction and relaxation, and reduced cardiac compliance [2].

It is well known that the prime determinant of the contractile properties, particularly the maximum shortening velocity, in the muscle cell is the catalytic activity of myofibrillar ATPase (my-ATPase) which resides in the head region of myosin heavy chain (MHC) [3]. On the basis of these findings, an inactivation of cardiac myATPase has been discussed as one of causes of diabetic cardiomyopathy. Two functionally diverse MHC isoforms are expressed in mammalian cardiomyocytes, i.e., $\alpha$-MHC and $\beta$-MHC. The two MHC isoforms display 93\% amino acid identity [4], yet $\alpha$-MHC exhibits more than two fold higher my-ATPase activity [5]. Diabetic cardiomyopathy has been demonstrated to be accompa nied by the downregulation of $\alpha$-MHC together with the upregulation of $\beta$-MHC, resulting in the decreased my-ATPase activity [6]. Therefore, the deteriorations in shortening velocity and power output that occur in diabetic heart are explained, in part, by a shift in MHC towards a slower phenotype. However, the maximum shortening velocity in diabetic cardiomyocyte declines more than would be expected from MHC isoform transitions [6], thus suggesting that other mechanisms are involved.

Reactive oxygen species (ROS), such as the superoxide anion, the hydroxyl radical and the hydrogen peroxide, are continuously produced in most cells under physiological conditions. Modest and transient increases in ROS play essential roles in the normal cellular signaling, whereas large and prolonged increases occur in pathological conditions. Diabetes has been shown to bring about ROS overproduction in cardiomyocytes due to mitochondrial abnormality [7] and NADPH oxidase activation [8]. These conditions are capable of activating a number of secondary messenger pathways, leading to cardiomyocyte apoptosis [9] and cardiac fibrosis [10] which contributes to compromise the cardiac function. 
It is generally accepted that, in skeletal muscles, severe oxidations of myofibrillar proteins (my-proteins) exert the deleterious effect on the functional behavior of the myofibril [11]. For instance, experiments on skinned fibers have indicated that exposures to ROS result in reductions in maximum force and/or the myofibrillar $\mathrm{Ca}^{2+}$ sensitivity $[12,13]$. The reductions seem likely to be owing, at least in part, to oxidation of cysteine residues, as the effects are at least partially reversible with the disulfide reducing agent. The additional effect of oxidative modification contributing to impaired myofibril function appears to be a decrease in the my-protein content, given that enhanced protein oxidation triggers protein degradation [14]. These findings on skeletal muscles raise the plausible hypothesis that diabetic cardiomyopathy might relate to not only $\mathrm{MHC}$ isoform transition, apoptosis and fibrosis, but also oxidation of the existing my-proteins. No published study presently exists, however, that examines a causal relationship among my-ATPase activity, my-protein content and oxidative modifications of myproteins in diabetic heart.

In this study, we tested the two hypotheses that 1) diabetes-induced disturbances in cardiac my-ATPase activity would be attributed to not only MHC isoform transitions, but also reductions in the MHC protein content (the first hypothesis); and 2) if diabetes results in declines in the MHC content, this change would relate to oxidative damage to MHC (the second hypothesis). To this end, diabetic hearts from the rats were analyzed for my-ATPase activity, and carbonyl and nitrotyrosine content. The present experiments conducted with the animals subjected to streptozotocin (STZ) injection reveal that depressions in my-ATPase activity and MHC content occur without concomitant elevations in carbonyl group, an indicator of protein oxidation, contained in MHC.

\section{Materials and Methods}

\subsection{Induction of Diabetes}

All procedures were approved by Animal Care Committee of Hiroshima University. The experiments were performed on male Wistar rats weighing between 200 and $250 \mathrm{~g}$. Throughout this study, the rats were housed at $22^{\circ} \mathrm{C}$ with fixed 12-h light/dark cycles and provided normal rat chow and water ad libitum. Diabetes was induced by a single intraperitoneal injection of STZ (65 $\mathrm{mg} / \mathrm{kg}$ body $\mathrm{wt}$ ) according to the method previously described [15]. Because STZ was dissolved in $0.1 \mathrm{M}$ citrate buffer ( $\mathrm{pH} 4.5$ ), control rats received citrate buffer only. Three days later, blood glucose levels were determined using Medisafe-Mini (GR0102, Terumo, Tokyo, Japan), and STZ-treated rats with higher than $12 \mathrm{mM}$ were considered diabetic according to Cai et al. [16]. Six weeks after the injection, hearts from each group $(n=8$ per each group) were excised under anethesia using pentobarbital sodium $(50 \mathrm{mg} / \mathrm{kg}$ body $\mathrm{wt})$. After papillary muscle experiments (see below), the atria and aorta were cut off, and the ventricular muscle tissues were supplied for biochemical analyses.

\subsection{Papillary Muscle Experiments}

Left ventricular papillary muscles were removed under the microscope and mounted between motionless lever and force transducer. The muscle chamber was perfused with Krebs-Ringer solution (in $\mathrm{mM}$ : $5 \mathrm{~N}, \mathrm{~N}$-bis(2-hydroxyethl)-2-aminoethanesulfonic acid, $5 \mathrm{KHCO}_{3}, 115$ $\mathrm{NaCl}, 20 \mathrm{NaHCO}_{3}, 1 \mathrm{MgCl}_{2}, 10$ glucose, 0.3 glutamic acid, 0.4 glutamine, and $2 \mathrm{CaCl}_{2}, 32^{\circ} \mathrm{C}$ ). The solution was continuously bubbled with $95 \% \mathrm{O}_{2}$ and $5 \% \mathrm{CO}_{2}$, which gives a bath $\mathrm{pH}$ 7.4. Papillary muscles were stimulated with $0.2 \mathrm{~Hz}$ and voltage $30 \%$ above threshold to contract for one hour equilibration period and set to optimal length according to the procedure previously described [17]. After steady-state conditions were obtained, twitch tension was recorded with PowerLab (ADInstruments, Tokyo, Japan). The mechanical properties evaluated in the experiment included peak twitch tension, time to peak tension (TPT), time to half relaxation $\left(\mathrm{TR}_{50}\right)$, and the mean rates of relaxation $(-\mathrm{dT} / \mathrm{dt})$ and force development $(+\mathrm{dT} / \mathrm{dt})$.

\subsection{Myofibrillar ATPase Activity}

Ventricular muscle myofibrils were prepared on ice as previously described [18]. Protein concentration was determined according to Bradford [19] using bovine serum albumin as a standard. My-ATPase activity was spectrophotometrically determined at $37^{\circ} \mathrm{C}$ according to the procedure previously described [20]. The reaction mixture was composed of $30 \mathrm{mM} \mathrm{KCl}, 30 \mathrm{mM}$ Tris, 1 mM EGTA, $2 \mathrm{mM} \mathrm{NaN}_{3}, 1 \mathrm{mM} \mathrm{MgSO}_{4}, 1.1 \mathrm{mM} \mathrm{CaCl}_{2}$, $0.4 \mathrm{mM}$ NADH, $10 \mathrm{mM}$ phosphoenolpyruvate, $18 \mathrm{U} \cdot \mathrm{ml}^{-1}$, pyruvate kinase and $18 \mathrm{U} \cdot \mathrm{ml}^{-1}$ lactate dehydrogenase. The reaction was started by adding ATP to give a final concentration of $1 \mathrm{mM}$. The oxidation of NADH was monitored in a spectrophotometer for $3 \mathrm{~min}(340 \mathrm{~nm})$.

\subsection{Isomyosin Electrophoresis}

The analytical procedure for pyrophosphate polyacrylamide gel electrophoresis (PAGE) has been described in detail elsewhere [21]. Briefly, after pre-electrophoresis for $30 \mathrm{~min}, 5 \mu \mathrm{g}$ protein was loaded on slab gel. Pyrophosphate-PAGE was carried out at $0^{\circ} \mathrm{C}$ with constant voltage of $120 \mathrm{~V}$ for $72 \mathrm{~h}$. The gels were silver-stained according to Oakley et al. [22]. The relative contents occupied by $V_{1}, V_{2}$ and $V_{3}$ were densitometrically estimated using Image $\mathrm{J}$. 


\subsection{Preperation of Myofibrillar Fraction}

The fraction enriched in my-proteins was prepared in ventricular muscles according to Thompson et al. [23]. The fractions were supplied for analyses of the MHC and actin protein contents and the redox state of my-proteins. Approximately $150 \mathrm{mg}$ of tissues was homogenized on ice in 8 volumes (mass vol ${ }^{-1}$ ) of a solution (solution 1) composed of $20 \mathrm{mM}$ imidazole and $0.25 \mathrm{mM}$ phenylmethyl sulfonyl fluoride ( $\mathrm{pH}$ 7.4). After centrifugation at $12,000 \mathrm{~g}$ for $15 \mathrm{~min}$ at $4^{\circ} \mathrm{C}$, the pellet was rehomogenized with solution 1 and the centrifugation was repeated. The pellet was then homogenized with 4 volumes (mass vol ${ }^{-1}$ ) of a solution (solution 2 ) consisting of $0.5 \%$ trifluoroacetic acid and $1 \mathrm{mM}$ tris(2-carboxyethylphosphine)hydrochloride. After centrifugation, the supernatant was collected and the remaining pellet was rehomogenized with solution 2 . After centrifugation, the supernatant was collected again. The two collected supernatants were combined and stored in $-80^{\circ} \mathrm{C}$.

\subsection{Myosin Heavy Chain and Actin Content}

In order to separate my-proteins, sodium dodecyl sulfate (SDS)-PAGE was performed using a $10 \%-20 \%$ (mass $\mathrm{vol}^{-1}$ ) gradient separating gel, as previously described [24]. Ten $\mu \mathrm{g}$ of protein was subjected to electrophoresis at $22^{\circ} \mathrm{C}$ for $5 \mathrm{~h}$, applying current of $20 \mathrm{~mA}$. The gels were stained with Coomassie blue R. The densitometrically estimated amounts of MHC and actin were normalized by reference to those in a standard my-protein.

\subsection{Immunoblotting}

Equal amounts of my-protein ( $7.5 \mu \mathrm{g}$ for carbonyl; $20 \mu \mathrm{g}$ for nitrotyrosine) were separated by SDS-PAGE described above. 2,4-dinitrophenylhydrazine (DNPH)-reactive carbonyls were detected by using Oxiblot kit (Chemicon international, Temecula, California, USA). After SDS-PAGE, proteins were transferred onto polyvinylidene difluoride membranes. The membranes were blocked in $1 \%\left(\right.$ mass vol $\left.^{-1}\right)$ bovine serum albumin, followed by incubation with the primary $(1: 150)$ and the secondary (1:300) antibodies for $1 \mathrm{~h}$ at $22^{\circ} \mathrm{C}$, respectively.

For nitrotyrosine immunoblotting, electrophoretically separated proteins were transferred onto nitrocellulose sheet. The blots were blocked in $3 \%$ (mass vol $^{-1}$ ) bovine serum albumin, followed by incubation with the antinitrotyrosine (1:1000; Cayman Chemical, Ann Arbor, Michigan, USA) at $4^{\circ} \mathrm{C}$ overnight. The blots were then incubated with a horseradish peroxidase-conjugated secondary antibody (1:50,000; polyclonal rabbit anti-mouse immunoglobulins, Dako, Glostrup, Denmark) at $22^{\circ} \mathrm{C}$ for $1 \mathrm{~h}$. Immunoreactive bands of carbonyl and nitrotyrosine were visualized using the enhanced chemiluminescence (ECL Western blotting detection reagents, Amersham Biosciences, Rockford, Illinois, USA). The intensities of bands were densitometrically evaluated. The carbonyl contents of MHC and actin were normalized by each protein content.

\subsection{Sulfhydryl Group Content}

The amounts of sulfhydryl (SH) group contained in myproteins were measured according to Favero et al. [25]. Fifty $\mu \mathrm{g}$ of proteins was incubated in a solution consisting of $50 \mathrm{mM}$ Tris- $\mathrm{HCl}(\mathrm{pH} 7.0), 1 \%\left(\right.$ mass $\mathrm{vol}^{-1}$ ) SDS, $1 \mathrm{mM}$ EDTA and $1 \mathrm{mM} \mathrm{5,5}$ ' dithiobis (2-nitrobenzoic acid) (DTNB) for $1 \mathrm{~h}$ at $22^{\circ} \mathrm{C}$. The $\mathrm{SH}$ group content was spectrophotometrically determined at a wavelength of $412 \mathrm{~nm}$.

\subsection{Lipid Peroxidation}

The method to measure products of lipid peroxidation was based on thiobarbituric acid (TBA) assays to measure malondialdehyde (MDA) according to Ohkawa et al. (1979) [26]. Approximately $100 \mathrm{mg}$ of muscle pieces was homogenized on ice in 5 volumes (mass $\mathrm{vol}^{-1}$ ) of $1.15 \%\left(\mathrm{mass} \mathrm{vol}^{-1}\right) \mathrm{KCl}$. The homogenates were added to a solution consisting of $20 \%\left(\mathrm{vol} \mathrm{vol}{ }^{-1}\right)$ acetic acid$\mathrm{NaOH}(\mathrm{pH} 3.5), 0.37 \%\left(\right.$ mass $\mathrm{vol}^{-1}$ ) SDS and $0.03 \%$ $\left(\right.$ mass vol ${ }^{-1}$ ) TBA. This solution was mixed, heated for 1 $\mathrm{h}$ at $100^{\circ} \mathrm{C}$, incubated on ice for $10 \mathrm{~min}$, and then centrifuged at $16,000 \mathrm{~g}$ for $10 \mathrm{~min}$ at $4^{\circ} \mathrm{C}$. The MDA content was spectrophotometrically determined in the supernatant at a wavelength of $532 \mathrm{~nm}$.

\subsection{Glutathione Content}

The amounts of total (GSH + GSSG) and oxidized glutathione (GSSG) were determined according to Baker et al. [27]. Approximately $50 \mathrm{mg}$ of muscle pieces was minced, placed on ice in 9 volumes (mass vol ${ }^{-1}$ ) of $5 \%$ (mass $\mathrm{vol}^{-1}$ ) 5 -sulfosalicylic acid for $30 \mathrm{~min}$, and then centrifuged at $16,000 \mathrm{~g}$ for $10 \mathrm{~min}$ at $4^{\circ} \mathrm{C}$. For $\mathrm{GSH}+$ GSSG measurement, $6 \%$ ( $\mathrm{vol} \mathrm{vol}^{-1}$; final concentration) triethanolamine was added to the supernatant, and for GSSG measurement, $2 \%$ ( $\mathrm{vol} \mathrm{vol}^{-1}$; final concentration) 2 -vinylpyridine was additionally added. The assay buffer contained $1.52 \mathrm{mM} \mathrm{NaH} \mathrm{PO}_{4}, 7.6 \mathrm{mM} \mathrm{Na} 2 \mathrm{HPO}_{4}, 0.485$ mM EDTA, $1 \mathrm{U} \mathrm{ml}^{-1}$ glutathione reductase and $0.1 \mathrm{mM}$ NADPH (pH 7.5). After the addition of an aliquot of the sample, the assay mixture was incubated for $2 \mathrm{~min}$. The reaction was started by adding 5,5'-dithiobis-(2-nitrobenzoic acid) to give a final concentration of $0.4 \mathrm{mM}$. The glutathione content was spectrophotometrically determined at a wavelength of $412 \mathrm{~nm}$. The content of reduced glutathione (GSH) was calculated as the difference 
between GSH + GSSG and GSSG contents. All biochemical measurements were performed in triplicate.

\subsection{Statistical Analysis}

Data are presented as the mean \pm SE. Student's unpaired $t$-tests were used to establish significant differences between control and diabetic rats. All comparisons were performed at a $95 \%$ confidence level.

\section{Results}

\subsection{General Characteristics of Animals and in Vitro Papillary Muscle Function}

Treatment with STZ resulted in significant reductions in the body and heart weights, which amounted to $65.0 \%$ and $73.1 \%$ of control, respectively (Table 1). The blood glucose level was 3.76-fold higher for diabetic than for control rats. Papillary muscles from diabetic rats displayed an inability to generate force (Table 1). Twitch tension, $+\mathrm{d} T / \mathrm{d} t$ and $-\mathrm{d} T / \mathrm{d} t$ were decreased to $76.6 \%$, $65.9 \%$ and $63.9 \%$ of control, respectively. Changes in $+\mathrm{d} T / \mathrm{d} t$ were accompanied by significant increases in TPT.

\subsection{Myofibrillar ATPase Activity, Isomyosin Distribution, and Myosin Heavy Chain and Actin Contents}

The catalytic activity of my-ATPase in diabetic ventricles was depressed to $66.5 \%$ of control (Figure 1). All three cardiac isomyosin, $\mathrm{V}_{1}\left(\alpha-\mathrm{MHC}\right.$ homodimer). $\mathrm{V}_{2}$ $\left(\alpha\right.$-MHC/ $\beta$-MHC heterodimer) and $\mathrm{V}_{3}(\beta$-MHC homodimer), were present in rat ventricles (Figure 2(a)). Ventricles of control rats displayed $\mathrm{V}_{1}$ as prominent isoforms $(76.1 \%)$ together with relatively low amounts of

Table 1. General characteristics of animals and contractile properties of left ventricular papillary muscle from 6-week STZ-induced diabetic and age-matched control rats.

\begin{tabular}{ccc}
\hline & Control & Diabetic \\
\hline Body wt $(\mathrm{g})$ & $430.0 \pm 6.0$ & $279.4 \pm 16.0^{\#}$ \\
Heart wt $(\mathrm{mg})$ & $1063.1 \pm 19.8$ & $777.0 \pm 19.6^{\#}$ \\
Blood glucose level $(\mathrm{mM})$ & $6.6 \pm 0.3$ & $24.8 \pm 1.6^{\#}$ \\
Twitch tension $\left(\mathrm{mN} / \mathrm{mm}^{2}\right)$ & $12.4 \pm 0.9$ & $9.5 \pm 0.9^{\#}$ \\
$+\mathrm{d} T / \mathrm{d} t\left(\mathrm{mN} / \mathrm{mm}^{2} / \mathrm{s}\right)$ & $91.3 \pm 6.8$ & $60.2 \pm 5.1^{\#}$ \\
$-\mathrm{d} T / \mathrm{d} t\left(\mathrm{mN} / \mathrm{mm}^{2} / \mathrm{s}\right)$ & $48.5 \pm 5.2$ & $31.0 \pm 2.6^{\#}$ \\
$\mathrm{TPT}(\mathrm{ms})$ & $134.3 \pm 5.5$ & $160.3 \pm 10.0^{\#}$ \\
$\mathrm{TR}_{50}(\mathrm{~ms})$ & $133.9 \pm 13.1$ & $154.5 \pm 11.6$ \\
\hline
\end{tabular}

Values are means $\pm \mathrm{SE}$ of $\mathrm{n}=8$ per group. STZ, streptozotocin; $+\mathrm{d} T / \mathrm{d} t$, rate of force development; $-\mathrm{d} T / \mathrm{d} t$, rate of relaxation; TPT, time to peak tension; $\mathrm{TR}_{50}$, time to half relaxation. ${ }^{\sharp} P<0.05$, significantly different from control.

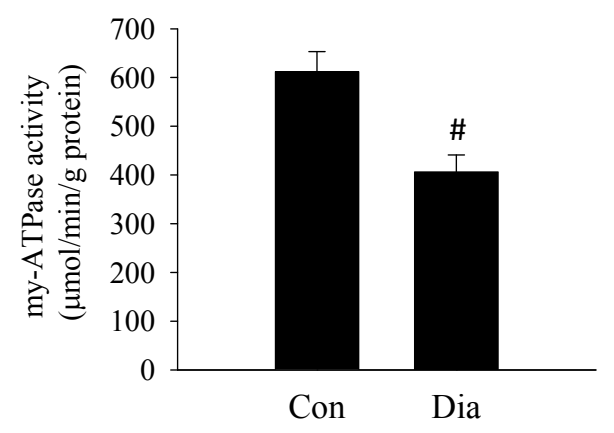

Figure 1. Myofibrillar ATPase (my-ATPase) activity in ventricles from 6-week STZ-induced diabetic and age-matched control rats. The catalytic activity of my-ATPase was measured in myofibril extracts. Values are means $\pm S E$ of $n=8$ per group. Con, control; Dia, diabetic; STZ, streptozotocin. ${ }^{\#} P<0.05$, significantly different from control.

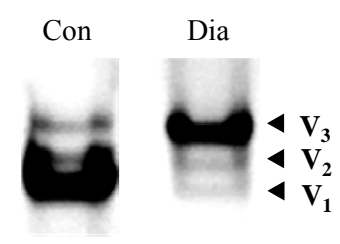

(a)

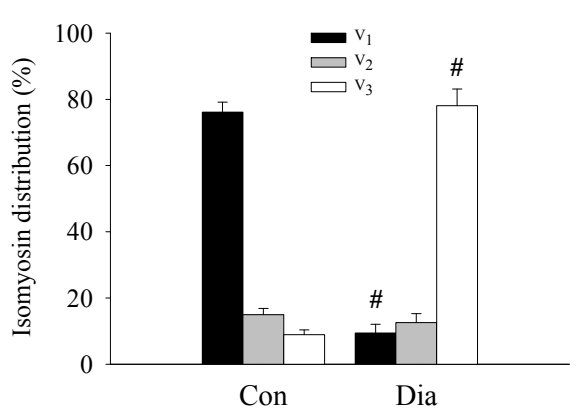

(b)

Figure 2. Electrophoretic separation of isomyosins (a) and percentage distribution of isomyosins (b) in ventricles from 6-week STZ-induced diabetic and age-matched control rats. Isomyosins were separated by electrophoresis under nondenaturing conditions. The percentage distribution of the three isomyosins was evaluated by the densitometry of silver-stained gels. Values are means $\pm \mathrm{SE}$ of $n=8$ per group. $\mathrm{V}_{1}, \alpha$-MHC homodimer; $\mathrm{V}_{2}, \alpha$-MHC/ $\beta$-MHC heterodimer; $\mathrm{V}_{3}, \boldsymbol{\beta}$-MHC homodimer; Con, control; Dia, diabetic; STZ, streptozotocin; MHC, myosin heavy chain. ${ }^{\#} P<0.05$, significantly different from control.

$\mathrm{V}_{2}(15.0 \%)$ and $\mathrm{V}_{3}(8.9 \%)$. In STZ-treated animals, the isomyosin pattern was shifted towards the slowest $\mathrm{V}_{3}$, which amounted to $78.0 \%$ of the total isomyosins (Figure 2(b)). $\mathrm{V}_{1}$ and $\mathrm{V}_{2}$ were found at relative concentrations of $9.4 \%$ and $12.6 \%$, respectively. STZ-treatment produced a significant decrease to $90.5 \%$ in the $\mathrm{MHC}$ content (Figure 3(b)). In contrast, an $8.4 \%$ decrease in the actin content did not reach statistical significance (Figure 3(c)). 


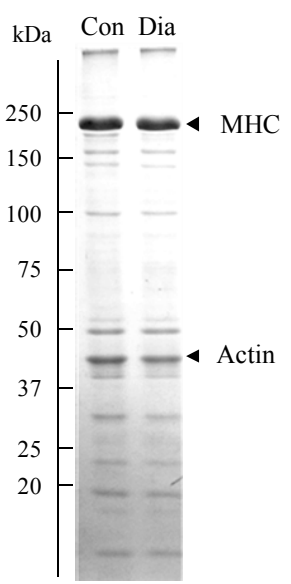

(a)

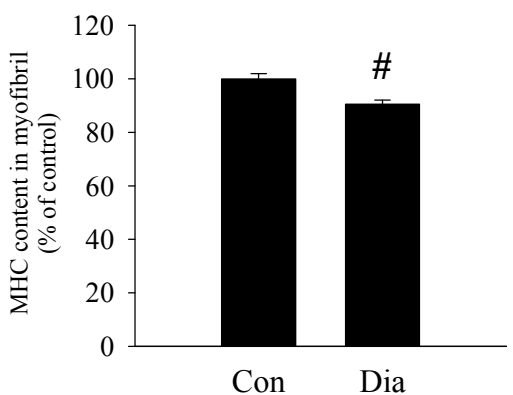

(b)

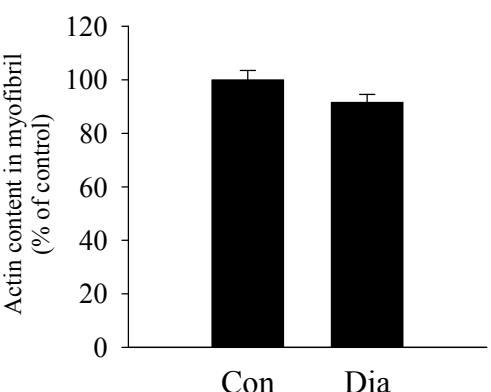

(c)

Figure 3. Electrophoresis of myofibrillar proteins (a) and myosin heavy chain (MHC) and actin protein contents ((b) and (c)) in ventricles from 6-week STZ-induced diabetic and age-matched control rats. Myofibrillar proteins were separated by polyacrylamide gradient $(10 \%-20 \%)$ gel electrophoresis. The contents of MHC and actin were evaluated by the densitometry of Coomassie blue-stained gels. The results are expressed as a percentage of control value. Values are means \pm SE of $n=8$ per group. Con, control; Dia, diabetic; STZ, streptozotocin. ${ }^{\#} P<0.05$, significantly different from control.

\subsection{Malondialdehyde and Glutathione Contents in Whole Muscle}

STZ-treatment resulted in a $31.0 \%$ increase in the MDA content (Figure 4). GSH is mostly present in mM levels in mammalian cells. A biological role has been suggested for endogenous GSH in alleviating oxidative stress. The GSH content in diabetic ventricles was increased to $129.7 \%$ of control (Figure 5(a)).

\subsection{Sulfhydryl, Carbonyl and Nitrotyrosine Contents in Myofibrillar Proteins}

No changes in the SH group content were found in myproteins from diabetic ventricles (Figure 6). The carbonyl group content contained in total my-proteins was markedly depressed in diabetic ventricles, which amounted to $66.6 \%$ of control (Figure 7(b)). As described above, density measures of the immunoblot were normalized to the MHC or actin contents. Thus, the ratio values (the density of immunoreaction/MHC or actin content) provides an estimate of the extent of oxidative modification. The carbonyl group content was significantly reduced in MHC, but not in actin (Figures 7(c) and (d)). In accordance with previous studies [28], nitrotyrosine was not detected in the MHC and actin bands (Figure 8(a)). There was no diabetes-related alteration in the nitrotyrosine content in total my-proteins (Figure 8(b)).

\section{Discussion}

Diabetes mellitus is a well-recognized risk factor for developing heart failure. Indeed, the frequency of heart failure has been shown to be twice in diabetic men and five times in diabetic women, compared to age-matched

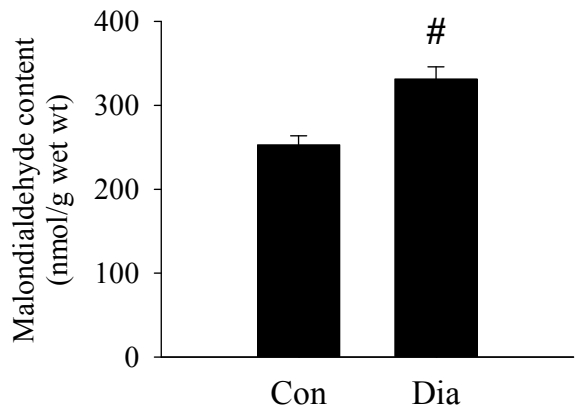

Figure 4. Malondialdehyde content in whole ventricles from 6-week STZ-induced diabetic and age-matched control rats. The malondialdehyde content were measured by thiobarbituric acid assays. Values are means \pm SE of $n=8$ per group. Con, control; Dia, diabetic; STZ, streptozotocin. ${ }^{\#} P<$ 0.05 , significantly different from control.

subjects [29]. Numerous studies on both human and rodent have provided evidence for systolic and diastolic dysfunction in diabetic ventricles [30]. Our results from mechanical analyses of papillary muscles agree with these findings in past studies.

The major findings in the current study are that diabetes-related decreases in my-ATPase activity were accompanied by reductions in the MHC content, but not by increases in the carbonyl content contained in MHC. The former confirms our first hypothesis, while the latter fails to support our second hypothesis (see Introduction). As evidenced by previous findings in animal studies and the present data, diabetic cardiomyocyte displays a shift of isomyosins from $\mathrm{V}_{1}$ with the highest my-ATPase activity to $\mathrm{V}_{3}$ with the lowest activity, leading to a decay of my-ATPase activity and eventually to systolic dysfunction [6]. However, the fact that the human heart primarily 


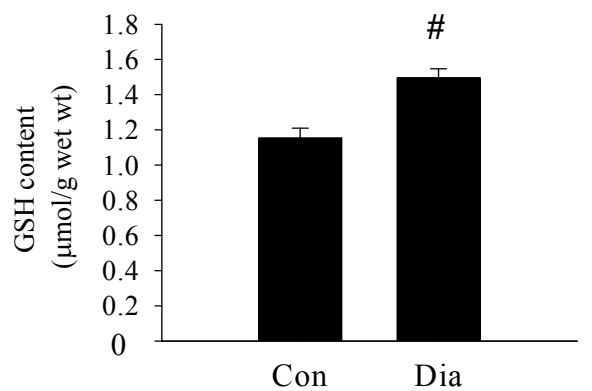

(a)

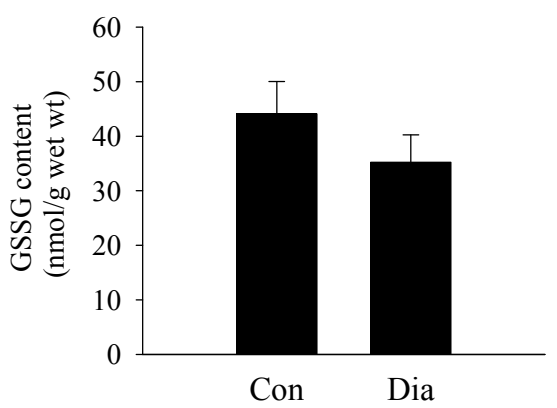

(b)

Figure 5. Glutathione content in whole ventricles from 6-week STZ-induced diabetic and age-matched control rats. Panels $A$ and $B$ show the contents of reduced glutathione (GSH) and glutathione disulfide (GSSG), respectively. Values are means $\pm S E$ of $\mathbf{n}=8$ per group. Con, control; Dia, diabetic; STZ, streptozotocin. ${ }^{\#} P<0.05$, significantly different from control.

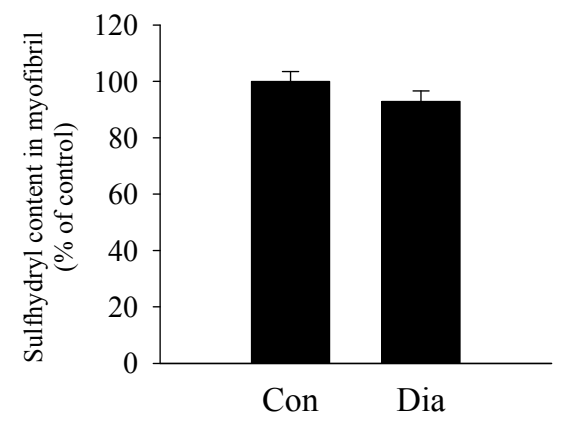

Figure 6. Sulfhydryl content in myofibrillar proteins from 6-week STZ-induced diabetic and age-matched control rat ventricles. The results are expressed as a percentage of control value. Values are means $\pm S E$ of $n=8$ per group. Con, control; Dia, diabetic; STZ, streptozotocin.

expresses $\mathrm{V}_{3}$ makes it unlikely that the shift of MHC is of physiological significance in diabetic cardiomyopathy at least in human. In contrast to the intensive research into MHC transitions, studies concerning the influence of diabetes on the MHC content are sparse. The only study by $\mathrm{Zu}$ et al. [31] revealed an approximately $80 \%$ reduction of the MHC content in mouse cardiac muscle 6 weeks after STZ injection. Although the magnitude of changes differs markedly, the diabetes-related altertions in the MHC content that we observed are qualitatively

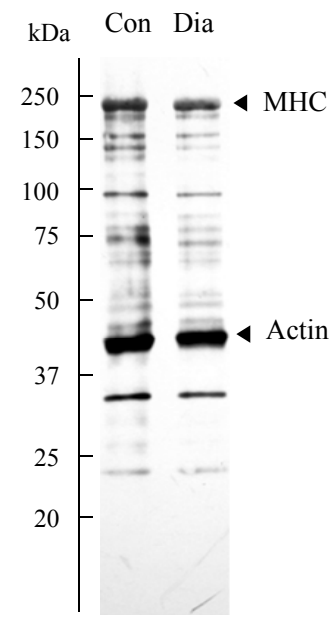

(a)

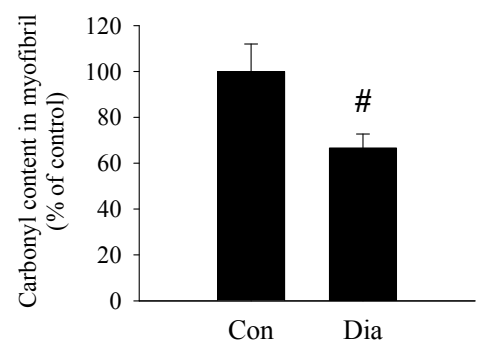

(b)

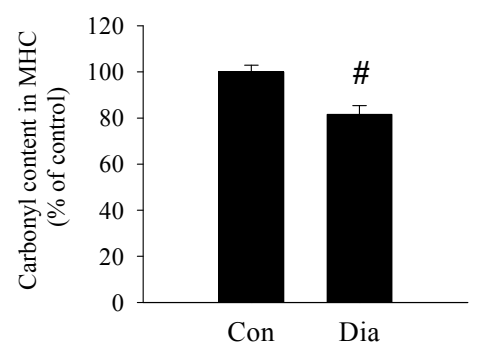

(c)

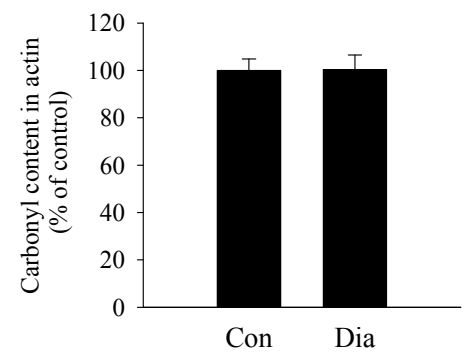

(d)

Figure 7. Immonoblot analysis of carbonyls and carbonyl content in myofibrillar proteins from 6-week STZ-induced diabetic and age-matched control rat ventricles. Panel A shows immunoblot labeled with anti-dinitrophenyl antibody. Panels B, C and D show the carbonyl contents in total myofibrillar proteins, myosin heavy chain (MHC) and actin, respectively. The carbonyl contents were evaluated by the densitometry of immunoblots. The results are expressed as a percentage of control value. Values are means \pm SE of $n=$ 8 per group. Con, control; Dia, diabetic; STZ, streptozotocin. ${ }^{\#} P<0.05$, significantly different from control. 


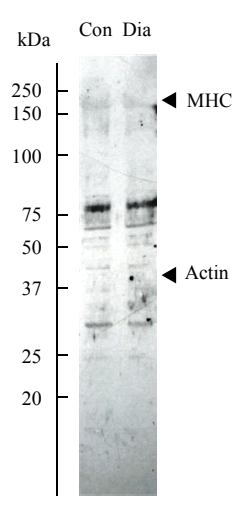

(a)

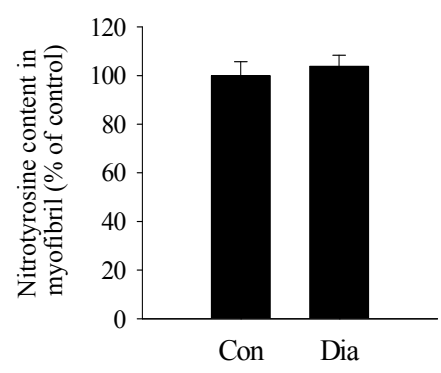

(b)
Figure 8. Immonoblot analysis of nitrotyrosines and nitrotyrosine content in myofibrillar proteins from 6-week STZinduced diabetic and age-matched control rat ventricles. Panel A shows immunoblot labeled with anti-nitrotyrosine antibody. Panel B shows the nitrotyrosine contents in total myofibrillar proteins. The nitrotyrosine contents were evaluated by the densitometry of immunoblots. The results are expressed as a percentage of control value. Values are means \pm SE of $n=8$ per group. Con, control; Dia, diabetic; STZ, streptzotocin.

similar to those of $\mathrm{Zu}$ et al. [31], suggesting that part of the decreased my-ATPase activity may be caused by a loss of MHC protein. The reasons for the quantitative difference in the results between the study of $\mathrm{Zu}$ et al. [31] and ours remain unclear, although differences in diabetogenic protocols employed, assay procedures, and/ or species appear to be involved.

It is a well-known fact that diabetes mellitus leads to increases in ROS production [8]. The elevated MDA content indicates a diabetes-induced shift of the redox state to the oxidized side in diabetic ventricles used in this study. Generally, the amount of a given protein present in muscle is regulated by the balance between protein synthesis and degradation. Enhanced protein oxidation seems likely to trigger protein degradation. It is proposed that since oxidized proteins are less thermostable than their native forms, they have to be eliminated, and that carbonylation and tyrosine nitration are irreversible modifications that require the proteolytic removal, thus accelerating protein degradation by the proteasomal system [14]. On the basis of these findings, we hypothesized that if diabetes results in declines in the MHC content, oxidative damage to MHC would be a one of the causes of the reduced MHC content (the second hypothesis). However, as judged by immunoblot analyses, our results do not provide evidence for oxidative damage to my-proteins (Figures 7 and 8). Support for the absence of oxidative modification also comes from our results of unaltered SH group present in my-proteins (Figure 6).
It is possible that the reduced MHC content could be linked to alterations in the rate of MHC synthesis. Studies with focus on transcriptional factors indicated that diabetes mellitus was responsible for nuclear factor ${ }_{\mathrm{K}} \mathrm{B}$ activation [32]. The activation seemed to trigger a cascade of signaling, which finally led to decreases and increases in $\alpha$ - and $\beta$-MHC gene expression, respectively. Although it is apparent that the nuclear factor ${ }_{\mathrm{K}} \mathrm{B}$ activation is capable of causing MHC isoform transitions mentioned above, further study will be required to elucidate whether this correlates with the diabetes-induced decay in $\mathrm{MHC}$ proteins.

An unexpected finding was the observation that STZinduced diabetes evoked reductions in the carbonyl content contained in MHC and my-proteins (Figure 7). This finding is difficult to explain in light of ROS overproduction in diabetic cardiomyocyte. Obviously, the reduced carbonyl is not caused by the reduced MHC, because our quantitative data shown in Figure 7 was normalized to the MHC content (see Meterials and Methods). A possible explanation of the decreased carbonyl is that alterations in the cellular redox state could result in improvement of the ability of the cell to protect intracellular organelles from the deleterious effect of ROS. GSH is the most important antioxidant in the muscle cell and serves as an antioxidant by reacting directly with ROS and by providing substrate for glutathione peroxidase. The literature on the impact of diabetic mellitus on the glutathione content in heart is controversial. Reductions in the ratio of GSH to GSSG [10], increases in GSH [6], and no changes in GSH [33] have been reported in diabetic ventricle. Although the cause for the discrepancies also remains unclear, the augmented amount of GSH shown in Figure 5(a) reveal the improved antioxidant ability, at least, in diabetic heart employed in this study.

This scenario, however, conflicts with our results of the MDA content. The increased MDA might be explained by a high susceptibility of lipids to ROS and by the site for ROS production. Superoxide generation has been shown to be augmented to $\sim 2$-fold in isolated mitochondria from diabetic mouse heart [9]. Mitochondria predominates in cardiac muscle and its inner membrane of mitochondria is the most susceptible region [30]. Moreover, superoxide that has a negative charge does not easily cross the mitochondrial membrane [34].

In summary, we show that diabetes-induced disturbances in my-ATPase activity occur in conjunction not only with MHC transitions towards a slower phenotype, but also with reductions in the MHC protein content. The reduced $\mathrm{MHC}$ content is not accompanied by elevations in DHNP-reactive carbonyls present in MHC. These results suggest that decreases in the MHC content may be associated, at least in part, with a diabetes-related inactivation of cardiac my-ATPase and may not be due to ac- 
cumulation of oxidative damage to protein. Future studies are needed to establish the mechanisms underlying diabetes-induced loss of MHC proteins.

\section{REFERENCES}

[1] S. Wild, G. Roglic, A. Green, R. Sicree and H. King, "Global Prevalence of Diabetes: Estimates for the Year 2000 and Projections for 2030," Diabetes Care, Vol. 27, No. 5, 2004, pp. 1047-1053. doi:10.2337/diacare.27.5.1047

[2] R. Tarquini, C. Lazzeri, L. Pala, C. M. Rotella and G. F. Gensini, "The Diabetic Cardiomyopathy," Acta Diabetologica, Vol. 48, No. 3, 2011, pp. 173-181. doi:10.1007/s00592-010-0180-x

[3] R. Bottinelli, "Functional Heterogeneity of Mammalian Single Muscle Fibres: Do Myosin Isoforms Tell the Whole Story?" Pflügers Archiv, Vol. 443, No. 1, 2001, pp. 6-17. doi:10.1007/s004240100700

[4] E. M. McNally, R. Kraft, M. Bravo-Zehnder, D. A. Taylor and L. A. Leinwand, "Full-Length Rat Alpha and Beta Cardiac Myosin Heavy Chain Sequences. Comparisons Suggest a Molecular Basis for Functional Differences," Journal of Molecular Biology, Vol. 210, No. 3, 1989, pp. 665-671. doi:10.1016/0022-2836(89)90141-1

[5] D. E. Harris, S. S. Work, R. K. Wright, N. R. Alpert and D. M. Warshaw, "Smooth, Cardiac and Skeletal Muscle Myosin Force and Motion Generation Assessed by CrossBridge Mechanical Interactions in Vitro," Journal of Muscle Research and Cell Motility, Vol. 15, No. 1, 1994, pp. 11-19. doi:10.1007/BF00123828

[6] L. E. Wold, A. F. Ceylan-Isik, C. X. Fang, X. Yang, S. Y. Li, N. Sreejayan, J. R. Privratsky and J. Ren, "Metallothionein Alleviates Cardiac Dysfunction in Streptozotocin-Induced Diabetes: Role of $\mathrm{Ca}^{2+}$ Cycling Proteins, NADPH Oxidase, Poly(ADP-Ribose) Polymerase and Myosin Heavy Chain Isozyme," Free Radical Biology and Medicine, Vol. 40, No. 8, 2006, pp. 1419-1429. doi:10.1016/j.freeradbiomed.2005.12.009

[7] S. Boudina and E. D. Abel, "Diabetic Cardiomyopathy Revisited," Circulation, Vol. 115, No. 25, 2007, pp. 32133223. doi:10.1161/CIRCULATIONAHA.106.679597

[8] N. D. Roe, D. P. Thomas and J. Ren, "Inhibition of NADPH Oxidase Alleviates Experimental Diabetes Induced Myocardial Contractile Dysfunction," Diabetes, Obesity and Metabolism, Vol. 13, No. 5, 2011, pp. 465473. doi:10.1111/j.1463-1326.2011.01369.x

[9] E. Shen, Y. Li, Y. Li, L. Shan, H. Zhu, Q. Feng, J. M. Arnold and T. Peng, "Rac1 Is Required for Cardiomyocyte Apoptosis during Hyperglycemia," Diabetes, Vol. 58, No. 10, 2009, pp. 2386-2395. doi:10.2337/db08-0617

[10] M. Aragno, R. Mastrocola, G. Alloatti, I. Vercellinatto, P. Bardini, S. Geuna, M. G. Catalano, O. Danni and G. Boccuzzi, "Oxidative Stress Triggers Cardiac Fibrosis in the Heart of Diabetic Rats," Endocrinology, Vol. 149, No. 1, 2008, pp. 380-388. doi:10.1210/en.2007-0877

[11] G. D. Lamb and H. Westerblad, "Acute Effects of Reactive Oxygen and Nitrogen Species on the Contractile
Function of Skeletal Muscle," The Journal of Physiology, Vol. 589, No. 9, 2011, pp. 2119-2127.

doi:10.1113/jphysiol.2010.199059

[12] R. M. Murphy, T. L. Dutka and G. D. Lamb, "Hydroxyl Radical and Glutathione Interactions Alter Calcium Sensitivity and Maximum Force of the Contractile Apparatus in Rat Skeletal Muscle Fibres," The Journal of Physiology, Vol. 586, No. 8, 2008, pp. 2203-2216. doi:10.1113/jphysiol.2007.150516

[13] T. L. Dutka, J. P. Mollica and G. D. Lamb, "Differential Effects of Peroxynitrite on Contractile Protein Properties in Fast- and Slow-Twitch Skeletal Muscle Fibers of Rat," Journal of Applied Physiology, Vol. 110, No. 3, 2011, pp. 705-716. doi:10.1152/japplphysiol.00739.2010

[14] J. Mary, S. Vougier, C. R. Picot, M. Perichon, I. Petropoulos and B. Friguet, "Enzymatic Reactions Involved in the Repair of Oxidized Proteins," Experimental Gerontology, Vol. 39, No. 8, 2004, pp. 1117-1123. doi:10.1016/j.exger.2004.06.008

[15] Y. Zhong, S. Ahmed, I. L. Grupp and M. A. Matlib, “Altered SR Protein Expression Associated with Contractile Dysfunction in Diabetic Rat Hearts," American Journal of Physiology-Heart and Circulatory Physiology, Vol. 281, No. 3, 2001, pp. H1137-H1147.

[16] L. Cai, W. Li, G. Wang, L. Guo, Y. Jiang and Y. J. Kang, "Hyperglycemia-Induced Apoptosis in Mouse Myocardium: Mitochondrial Cytochrome C-Mediated Caspase-3 Activation Pathway," Diabetes, Vol. 51, No. 6, 2002, pp. 1938-1948. doi:10.2337/diabetes.51.6.1938

[17] N. Takeda, P. Dominiak, D. Turck, H. Rupp and R. Jacob, "Myocardial Catecholamine Responsiveness of Spontaneously Hypertensive Rats as Influenced by Swimming Training," Basic Research in Cardiology, Vol. 80, No. 4, 1985, pp. 384-391. doi:10.1007/BF01908182

[18] R. W. Tsika, R. E. Herrick and K. M. Baldwin, "Interaction of Compensatory Overload and Hindlimb Suspension on Myosin Isoform Expression," Journal of Applied Physiology, Vol. 62, No. 6, 1987, pp. 2180-2186.

[19] M. M. Bradford, "A Rapid and Sensitive Method for the Quantitation of Microgram Quantities of Protein Utilizing the Principle of Protein-Dye Binding," Analytical Biochemistry, Vol. 72, No. 1-2, 1976, pp. 248-254. doi:10.1016/0003-2697(76)90527-3

[20] K. Kanzaki, M. Kuratani, T. Mishima, S. Matsunaga, N. Yanaka, S. Usui and M. Wada, "The Effects of Eccentric Contraction on Myofibrillar Proteins in Rat Skeletal Muscle," European Journal of Applied Physiology, Vol. 110, No. 5, 2010, pp. 943-952. doi:10.1007/s00421-010-1579-3

[21] M. Wada, N. Hamäläinen and D. Pette, "Isomyosin Patterns of Single Type IIB, IID and IIA Fibres from Rabbit Skeletal Muscle," Journal of Muscle Research and Cell Motility, Vol. 16, No. 3, 1995, pp. 237-342. doi:10.1007/BF00121132

[22] B. R. Oakley, D. R. Kirsch and N. R. Morris, "A Simplified Ultrasensitive Silver Stain for Detecting Proteins in Polyacrylamide Gels," Analytical Biochemistry, Vol. 105, No. 2, 1980, pp. 361-363. doi:10.1016/0003-2697(80)90470-4 
[23] L. V. Thompson, D. Durand, N. A. Fugere and D. A. Ferrington, "Myosin and Actin Expression and Oxidation in Aging Muscle," Journal of Applied Physiology, Vol. 101, No. 6, 2006, pp. 1581-1587. doi:10.1152/japplphysiol.00426.2006

[24] T. Yamada, T. Mishima, M. Sakamoto, M. Sugiyama, S. Matsunaga and M. Wada, "Oxidation of Myosin Heavy Chain and Reduction in Force Production in Hyperthyroid Rat Soleus," Journal of Applied Physiology, Vol. 100, No. 5, 2006, pp. 1520-1526. doi:10.1152/japplphysiol.01456.2005

[25] T. G. Favero, D. Colter, P. F. Hooper and J. J. Abramson, "Hypochlorous Acid Inhibits $\mathrm{Ca}^{2+}$-ATPase from Skeletal Muscle Sarcoplasmic Reticulum," Journal of Applied Physiology, Vol. 84, No. 2, 1998, pp. 425-430.

[26] H. Ohkawa, N. Ohishi and K. Yagi, "Assay for Lipid Peroxides in Animal Tissues by Thiobarbituric Acid Reaction," Analytical Biochemistry, Vol. 95, No. 2, 1979, pp. 351-358. doi:10.1016/0003-2697(79)90738-3

[27] M. A. Baker, G. J. Cerniglia and A. Zaman, "Microtiter Plate Assay for the Measurement of Glutathione and Glutathione Disulfide in Large Numbers of Biological Samples," Analytical Biochemistry, Vol. 190, No. 2, 1990, pp. 360-365. doi:10.1016/0003-2697(90)90208-Q

[28] T. Yamada, N. Place, N. Kosterina, T. Ostberg, S. J. Zhang, C. Grundtman, H. Erlandsson-Harris, I. E. Lundberg, B. Glenmark, J. D. Bruton and H. Westerblad, "Impaired Myofibrillar Function in the Soleus Muscle of Mice with Collagen-Induced Arthritis," Arthritis and Rheumatism, Vol. 60, No. 11, 2009, pp. 3280-3289.

doi:10.1002/art.24907
[29] W. B. Kannel and D. L. McGee, "Diabetes and Cardiovascular Disease. The Framingham Study," The Journal of the American Medical Association, Vol. 241, No. 19, 1979, pp. 2035-2038. doi:10.1001/jama.1979.03290450033020

[30] Y. Tang, C. Gao, M. Xing, Y. Li, L. Zhu, D. Wang, X. Yang, L. Liu and P. Yao, "Quercetin Prevents EthanolInduced Dyslipidemia and Mitochondrial Oxidative Damage," Food and Chemical Toxicology, Vol. 50, No. 5, 2012, pp. 1194-1200. doi:10.1016/j.fct.2012.02.008

[31] L. Zu, D. Bedja, K. Fox-Talbot, K. L. Gabrielson, L. V. Kaer, L. C. Becker and Z. P. Cai, "Evidence for a Role of Immunoproteasomes in Regulating Cardiac Muscle Mass in Diabetic Mice," Journal of Molecular and Cellular Cardiology, Vol. 49, No. 1, 2010, pp. 5-15. doi:10.1016/j.yjmcc.2010.02.007

[32] M. Aragno, R. Mastrocola, C. Medana, M. G. Catalano, I. Vercellinatto, O. Danni and G. Boccuzzi, "Oxidative StressDependent Impairment of Cardiac-Specific Transcription Factors in Experimental Diabetes," Endocrinology, Vol. 147, No. 12, 2006, pp. 5967-5974. doi:10.1210/en.2006-0728

[33] Q. Liang, E. C. Carlson, R. V. Donthi, P. M. Kralik, X. Shen and P. N. Epstein, "Overexpression of Metallothionein Reduces Diabetic Cardiomyopathy," Diabetes, Vol. 51, No. 1, 2002, pp. 174-181. doi:10.2337/diabetes.51.1.174

[34] D. G. Allen, G. D. Lamb and H. Westerblad, "Skeletal Muscle Fatigue: Cellular Mechanisms," Physiological Reviews, Vol. 88, No. 1, 2008, pp. 287-332. doi:10.1152/physrev.00015.2007 